\title{
O dispositivo midiático: da conceituação foucaultiana à aplicação nos estudos comunicacionais*
}

\author{
Marco Túlio de Sousa* \\ Carlos Alberto de Carvalho ${ }^{* \star *}$
}

Recibido: 2017-06-21 • Enviado a pares: 2017-09-10

Aprobado por pares: 2017-10-06 Aceptado: 2017-11-11

DOI: 10.22395/angr.v16n32a2

\begin{abstract}
Resumo
No artigo retomamos o conceito de "dispositivo" de Michel Foucault e procuramos aplicálo aos estudos comunicacionais. Para tanto, fizemos uma revisão bibliográfica a partir do próprio Foucault e dos seus comentadores Agamben e Deleuze. Em seguida, cotejamos as contribuições de pesquisadores do campo da comunicação (Antunes, Vaz; Mouillaud; Ferreira) que também fazem uso do termo "dispositivo", sejam ancorados na abordagem foucaultiana ou em outras perspectivas. A partir desse percurso, apresentamos algumas contribuições a fim de alinhar a perspectiva de Foucault às especificidades da mídia como objeto de estudo.
\end{abstract}

Palavras-chave: Deleuze; Dispositivo; Dispositivo Midiático; Foucault; Mídia.

\footnotetext{
Este artigo é resultado de discussões realizadas no âmbito da linha de pesquisa Textualidades Midiáticas e do grupo de estudos Tramas Comunicacionais Narrativas e Experiência vinculados ao Programa de Pós-graduação em Comunicação Social da Universidade Federal de Minas Gerais (UFMG). As pesquisas que permitiram a escrita contaram com apoios financeiros do Conselho Nacional de Desenvolvimento Científico e Tecnológico e da Fundação de Apoio à Pesquisa de Minas Gerais (Brasil).

." Doutorando em Comunicação pela Universidade do Vale do Rio dos Sinos. Mestre em Comunicação pela Universidade Federal de Minas Gerais. Graduado em Comunicação com habilitação em Jornalismo pela Universidade Federal de Juiz de Fora. É bolsista de doutorado do Conselho Nacional de Desenvolvimento Científico e Tecnológico (CNPq) e desenvolve pesquisas sobre mídia e religião.E-mail: marcotuliosousa@hotmail.com. https://orcid.org/0000-00030186-7266

... Professor do Departamento de Comunicação Social da Universidade Federal de Minas Gerais (UFMG), atuante na graduação e no Programa de Pós-Graduação em Comunicação. Doutor e mestre em Comunicação pela UFMG e graduado em Comunicação com habilitação em Jornalismo pela mesma universidade. Desenvolve pesquisas sobre jornalismo, AIDS e Homofobia, com financiamento da Fundação de Amparo à Pesquisa do Estado de Minas Gerais (FAPEMIG) e do Conselho Nacional de Desenvolvimento Científico e Tecnológico (CNPq). E-mail: carloscarvalho0209@gmail. com. http://orcid.org/0000-0001-8433-8794
} 


\title{
El dispositivo mediático: del concepto foucaultiano a la aplicación en los estudios comunicacionales
}

\author{
Resumen \\ En el artículo retomamos el concepto de dispositivo de Michel Foucault y buscamos \\ aplicarlo a los estudios comunicacionales. Por lo tanto, hicimos una revisión bibliográfica \\ desde el mismo Foucault y sus comentadores Agamben y Deleuze. En seguida, cotejamos \\ las contribuciones de investigadores del campo de la comunicación que también hacen uso \\ del término "dispositivo", sean basados en el abordaje foucaultiano o en otras perspectivas. \\ A partir de ese recorrido, presentamos nuestra contribución en la cual buscamos alinear la \\ perspectiva de Foucault a las especificidades de los medios como objeto de estudio. \\ Palabras clave: Deleuze; Dispositivo; Dispositivo Mediático; Foucault; Medios.

\section{The media device: from the Foucauldian concept to the application in communication studies}

\begin{abstract}
In this article, we return to the concept of Michel Foucault's device and we seek to apply it to communication studies. Therefore, we made a bibliographic review of Foucault and his commentators: Agamben, and Deleuze. After that, we compared the contributions of researchers in the field of communication who also use the term "device", whether based on the Foucauldian approach or on other perspectives. From this journey, our contribution is presented here, in which we seek to align Foucault's perspective to the specificities of the media as an object of study.
\end{abstract}

Keywords: Deleuze; device; media device; Foucault; media. 


\section{Introdução}

É recorrente encontrarmos o termo "dispositivo" em trabalhos acadêmicos da área da Comunicação e, muitas dessas vezes, ele não é utilizado como um conceito que problematiza questões, mas com o sentido mais próximo daquilo que já está incorporado ao senso comum, qual seja, como objeto da ordem do universo tecnológico, a exemplo dos tablets e celulares, também chamados no Brasil de "dispositivos móveis". Tal acepção costuma aparecer também em artigos que versam sobre os dispositivos midiáticos e mesmo em estudos que derivam desse termo algum teor explicativo.

Embora reconheçamos que a dimensão da técnica e (ou) da tecnologia corresponde a propriedades do que se denomina "dispositivo", é preciso frisar que o conceito na forma como foi concebido por Michel Foucault (2012) não se limita a esse aspecto. Muito pelo contrário, a técnica ou a tecnologia consistem em apenas uma das dimensões envolvidas nas complexas relações de poder que o dispositivo tece ou que nele são tecidas pelos sujeitos em suas experiências.

No presente trabalho recuperamos a abordagem foucaultiana do dispositivo e procuramos apontar de que modo ela se mostra produtiva para pensar questões comunicacionais.

\section{Metodologia}

Tendo em vista que se trata de uma discussão de caráter conceitual abordamos a temática por meio de revisão de literatura. Portanto, ao longo do texto apresentaremos a concepção de "dispositivo" segundo as proposições originais de Foucault e das releituras que Deleuze e Agamben fazem baseando-se no autor francês. De modo semelhante também recorreremos a autores como Bruck, Ferreira, Mouillaud e Antunes\&Vaz. Tais pesquisadores, tomando como ponto de partida as reflexões mais gerais sobre o "dispositivo", propõem o conceito de "dispositivo midiático" e, embora se distanciem das discussões de Foucault sobre as relações de poder, oferecem-nos contribuições produtivas para se pensar as mídias.

Nosso desafio, portanto, consiste em preservar os avanços já feitos por esses autores, mas sem abrir mão da visada foucaultiana, que consideramos fundamental para compreendermos o que estamos denominando "dispositivo midiático". Trata-se, assim, de articular contribuições originárias do campo filosófico para pensar modos como as mídias se apresentam segundo as lógicas do dispositivo, o que nos permite vislumbrá -las para além de noções que, não raramente, estão mais focadas em suas qualidades técnicas e materiais, e deixam em segundo plano suas dimensões de poder e de locais de circulação de discursos. Procedemos, portanto, à seleção de textos e autores inscritos nos domínios das reflexões filosóficas e das reflexões sobre as mídias que têm em comum o desafio de compreensão dos dispositivos em suas aberturas de sentido e em sua desafiadora polissemia. 


\section{O que é um dispositivo}

Comecemos pelo sentido dicionarizado do termo "dispositivo". Tendo em vista que dicionários são instrumentos de estabilização de sentidos que têm como funcionalidade informar qual entendimento de uma palavra é mais aceitável em determinada época, pensamos ser interessante apresentar a definição tal como exposta nesse contexto a fim de que possamos tanto esclarecer em que ela difere da conceituação proposta por Foucault, quanto perceber pistas daquilo que o autor compreende como "dispositivo". No dicionário Michaelis, em sua versão on-line $e^{1}$ consultado no ano de 2013, encontramos como definições para dispositivo:

ADJ (lat dispositus+ivo) 1 Próprio para dispor. 2 Que contém ordem, prescrição, disposição; determinativo. SM 1 Regra, preceito. 2 Dir. Artigo de lei. 3 Qualquer peça ou mecanismo de uma máquina destinados a uma função especial. 4 Inform. Cada uma das várias peças úteis ou máquinas menores de um equipamento. Exemplos: controlador de vídeo, leitora de cartão magnético, mouse, etc. D. apontador, Inform: dispositivo de entrada que controla a posição de um cursor na tela conforme esse é movido pelo usuário. V também mouse. D. de apontamento relativo, Inform: dispositivo de entrada (como um mouse). D. de blocos, Inform: dispositivo que manipula vários bytes de dados de uma vez. Ex: unidade de disco. D. de entrada/saída, Inform: V unidade de entrada/saída. D. multidisco, Inform: dispositivo que utiliza diversos tamanhos e formatos de discos. D. MIDI, Inform: dispositivo que pode receber ou enviar dados MIDI. (Michaelis, 2013, grifos nossos)

Nas definições 3 e 4 aparecem sentidos que ressoam amiúde no senso comum, ou seja, dispositivo é "qualquer peça ou mecanismo de uma máquina destinadas a uma função especial" ou consiste em "cada uma das várias peças úteis ou máquinas menores de um equipamento". Tais aspectos, juntamente com os exemplos do excerto, nos mostram uma acepção técnica ou meramente tecnológica, dimensão esta que permanece em alguma medida na conceituação foucaultiana, mas que, no entanto, não se limita à ela. $\mathrm{O}$ próprio termo "mecanismo" sugere certa dureza ao implicar uma repetição constante e ordenada de uma ação.

Para os nossos propósitos é importante observar que "dispositivo" corresponde a um organizar, a um ordenar. Assim, conforme consta nas definições, a maneira com que o dispositivo funciona diz respeito a um "1 - modo próprio para dispor", a algo que "2 - contém ordem, prescrição, disposição; determinativo". As definições 1 e 2 nos dão valiosas indicações. A partir delas podemos nos arriscar a dizer que o dispositivo tem como propriedade organizar algo (ou alguém) de uma determinada forma. Assim, o dispositivo convoca aquilo (ou aquele) que ele organiza em determinadas ações, estabelecendo formas adequadas e inadequadas de agir enquanto está circunscrito à sua esfera de influência ou, passando à abordagem foucaultiana, enquanto permanece nas teias de relações de poder que o dispositivo deixa ver.

Dicionário Michaelis. Recuperado em 10 de julho de 2013. Disponível em: <http://michaelis.uol.com.br/> 
Este brevíssimo exercício interpretativo nos mostra que os sentidos do termo em questão vão muito além de sua designação de âmbito técnico ou tecnológico. "Dispositivo" diz a respeito a um modo próprio (diferenciado, portanto) de organizar, de dispor (pôr ou colocar de alguma forma). Avançando na discussão e aproximando-a de Foucault, poderíamos dizer que tem a ver com os indivíduos que se relacionam com esses dispositivos, interferindo em tais modos de organização e/ou sendo organizados por eles. No entanto, como veremos a seguir, a proposição foucaultiana escapa a qualquer determinismo, uma vez que as condições de manutenção do poder são dialéticas e, portanto, tanto geram as condições para que ele seja mantido, quanto superado.

\section{Foucault, Agamben e o lugar do dispositivo}

Embora Foucault não tenha se identificado como estruturalista e tampouco tenha aceitado o rótulo de pós-estruturalista, é comum que ele seja colocado nos limites da primeira corrente ou como um dos expoentes da segunda por seus comentadores (Cezar, 1995). Não entraremos nos detalhes dessa polêmica, uma vez que foge ao escopo deste trabalho. O que nos importa é precisar minimamente os sentidos que a noção de dispositivo adquire no pensamento de Foucault a fim de analisarmos as implicações deste conceito, que aparece explicitamente formulado em alguns raros momentos de sua obra.

Em Estruturalismo e Pós-Estruturalismo na Perspectiva do Conhecimento Histórico (1995), Temístocles Cezar oferece uma síntese do que foram tais correntes e de que modo elas afetaram a forma como a História é pensada na academia. Ao percorrer autores como Saussure, Lévi-Strauss, Althusser, entre outros, o autor faz um inventário das principais concordâncias e discordâncias de Foucault em relação ao estruturalismo.

Foucault mantém-se atrelado a certas premissas comuns ao estruturalismo, tais como a ausência do sujeito, a destituição do homem como objeto central das ciências humanas e a descontinuidade histórica; e inversamente àquele paradigma para Foucault a inscrição da historicidade em suas próprias pesquisas é uma premissa inconteste, além de não mostrar-se convencido das possibilidades formais apresentadas por um sistema como linguagem. (Cezar, 1995, pp. 136-137, grifos do autor)

Segundo Cezar, Foucault procurou se afastar do estruturalismo ao desviar de temas e investigações que poderiam levar a invariantes universais. Deleuze (1996) aponta que em Foucault o conceito de "dispositivo" surge como uma alternativa aos universais totalizantes que regeram as ciências humanas, como a ideia de uma Razão consensual e universal que libertaria os homens do seu oposto, qual seja, a completa alienação. O caráter universal da noção de "dispositivo" não trai o projeto de pesquisa do autor, pelo contrário, ao funcionar como um universal não totalizante, o dispositivo faz emergir problemas em vez de sacar uma solução definitiva para questões particulares.

O termo "dispositivo" só foi aparecer em Foucault tardiamente, mais precisamente na década de 1970. Não obstante, a ideia contida nele perpassa toda sua obra. A discussão de Foucault sobre as instituições e a formação da subjetividade do indivíduo se alicerça nesse conceito-chave, que tem sido retomado constantemente nas mais diversas inves- 
tigações. Vamos nos basear nas leituras da obra de Foucault feitas por Agamben (2005) e Deleuze (1996) a fim de problematizarmos possíveis atribuições do termo.

Uma das primeiras dificuldades em se falar de "dispositivo" consiste no fato de Foucault ter utilizado pouco o termo, além de não ter apresentado uma acepção definitiva para ele. Ao realizar uma genealogia do dispositivo, Agamben (2005) aponta que o que mais se aproxima do conceito na obra do autor consiste no termo "positividade". Em A Arqueologia do Saber, livro de 1969, "positividade" é entendida como algo da ordem de uma historicidade regida por relações de poderes que se presentifica nas enunciações individuais. Assim, "a positividade de um discurso - como o da história natural, da economia política, ou da medicina clínica - caracteriza-lhe a unidade do tempo e muito além das obras individuais, dos livros e dos textos" (Foucault, 2012, p. 154).

A positividade corresponde a um a priori histórico, ou seja, uma condição necessária para que alguns enunciados possam ser pronunciados e adquiram certos sentidos em detrimento de outros. Isso está diretamente ligado às relações de poder que são tecidas na interação entre indivíduos e dispositivos. Nas palavras de Agamben (2005), podemos dividir tudo que existe em dispositivos e seres viventes. Os sujeitos emergem a partir do momento em que indivíduos são interpelados ou, podemos também dizer, são capturados pelos dispositivos.

De acordo com o pensador italiano, a palavra "dispositivo" começa a aparecer com mais frequência na obra de Foucault quando ele passa a se dedicar àquilo que chama de "governabilidade" ou "governo dos homens". Em uma entrevista no ano de 1977, Foucault chega a sugerir uma breve caracterização para o que ele chama de "dispositivo". Agamben (2005) a resume em três pontos.

1) [O dispositivo] é um conjunto heterogêneo, que inclui virtualmente qualquer coisa, linguístico e não-linguístico no mesmo título: discursos, instituições, edifícios, leis, medidas de segurança, proposições filosóficas etc. O dispositivo em si mesmo é a rede que se estabelece entre esses elementos.

2) O dispositivo tem sempre uma função estratégica concreta e se inscreve sempre em uma relação de poder.

3) É algo de geral (un reseau, uma 'rede') porque inclui em si a episteme, que para Foucault é aquilo que em uma certa sociedade permite distinguir o que é aceito como um enunciado científico daquilo que não é científico. (Agamben, 2005, p. 10, grifos nossos)

O dispositivo funciona para Foucault como um universal que vai de encontro a proposições filosóficas que tratam de uma universalidade inerente a um sujeito fundador, de uma Razão única que levaria ao consenso e à ordem. Nesse sentido, embora o dispositivo processualmente se assemelhe a um universal, ele não possui o caráter totalizante, tal como os conceitos criticados pelo autor. Pelo contrário, a perspectiva do dispositivo nos indica um modo de pensar nas bifurcações da Razão ou uma alienação que se acredita absoluta, oferecendo, portanto, meios de tensioná-las. 
Em um exercício interpretativo, Agamben procura avançar na discussão foucaultiana ampliando a aplicação do conceito de dispositivo. Assim,

Generalizando posteriormente a já amplíssima classe dos dispositivos foucaultianos, chamarei literalmente de dispositivo qualquer coisa que tenha de algum modo a capacidade de capturar, orientar, determinar, interceptar, modelar, controlar e assegurar os gestos, as condutas, as opiniões e os discursos dos seres viventes. Não somente, portanto, as prisões, os manicômios, o panóptico (sic), as escolas, as confissões, as fábricas, as disciplinas, as medidas jurídicas etc, cuja conexão com o poder é em um certo sentido evidente, mas também a caneta, a escritura, a literatura, a filosofia, a agricultura, o cigarro, a navegação, os computadores, os telefones celulares e - porque não - a linguagem mesma, que é talvez o mais antigo dos dispositivos, em que há milhares e milhares de anos um primata - provavelmente sem dar-se conta das consequências que se seguiriam - teve a inconsciência de se deixar capturar. (Agamben, 2005, p. 13, grifos nossos)

Tendo em vista que os indivíduos se relacionam cotidianamente com vários tipos de dispositivos, isso significa dizer que passam por inúmeros processos de subjetivação e se relacionam com diversas instâncias de poder. No tocante à mídia, o autor fala brevemente do celular e da televisão em seu texto. Contudo, para ele, os dispositivos midiáticos apontam não para processos de subjetivação, mas, pelo contrário, eles nos levariam ao inverso desse processo.

Aquele que se deixa capturar no dispositivo "telefone celular", qualquer que seja a intensidade do desejo que o impulsionou, não adquire, para isso, uma nova subjetividade, mas somente um número através do qual pode ser, eventualmente, controlado; o espectador que passa as suas noites diante da televisão não recebe mais, em troca da sua dessubjetivacão, que a máscara frustrante do zappeur ou a inconclusão no cálculo de um índice de audiência. Daqui a futilidade daqueles discursos bem intencionados sobre a tecnologia, que afirmam que o problema dos dispositivos se reduz àquele de seu uso correto. Esses discursos parecem ignorar que, se todo dispositivo corresponde a um determinado processo de subjetivação (ou, neste caso, de dessubjetivação), é de todo impossível que o sujeito do dispositivo o use "de modo justo". Aqueles que têm discursos similares são, de resto, a seu tempo, o resultado do dispositivo midiático no qual estão capturados. (Agamben, 2005, p. 15 , grifos nossos)

A crítica de Agamben ao dispositivo midiático se expande para outros dispositivos. No entanto, em tal crítica ele acaba se afastando da perspectiva de Foucault. No tocante ao dispositivo midiático, Agamben parece se restringir à esfera da enunciação, sem considerar as complexas dinâmicas de circulação, apropriação e significação dos textos midiáticos pelo público.

Além disso, dizer que os dispositivos midiáticos levam a processos de dessubjetivação implicaria ir na contramão de uma das operações essenciais do dispositivo, qual seja: constituir sujeitos. Logo, não poderíamos considerar os dispositivos midiáticos como dispositivos se seguíssemos esse raciocínio, visto que em vez de fazerem emer- 
gir sujeitos eles operariam no sentido contrário. Curioso notar que Agamben critica justamente um discurso acadêmico que resume a mídia à mera problemática do seu "uso correto".

Não obstante, ao dizer que os dispositivos midiáticos não fazem emergir novas subjetividades o que sobra dessa visão de dispositivo é justamente uma compreensão fechada, diferente da perspectiva dialética e dinâmica proposta por Foucault que percebe no dispositivo um lugar que faz emergir sujeições, mas também subjetividades que permitem, inclusive, tensionar o dispositivo. Em Profanações, outra obra de Agamben, tal crítica reaparece: "os dispositivos midiáticos têm como objetivo, precisamente, neutralizar esse poder profanatório da linguagem como meio puro, impedir que o mesmo abra a possibilidade de um novo uso, de uma nova experiência da palavra" (Agamben, 2007, p. 76).

A "profanação", termo que dá nome à obra, diz respeito a uma restituição daquilo que foi separado pelos dispositivos ao uso comum. Se a consagração remete a um corte, no qual lugares são atribuídos aos seres e modos de agir são autorizados e proibidos, a profanação se refere a uma subversão daquilo que foi consagrado, separado, e que é tornado profano, de acesso comum. Na obra referida, Agamben nos incita a profanar os dispositivos, ou seja, neutralizá-los e devolver à coletividade o que dela havia sido retirado (Agamben, 2007, p. 68).

Embora o projeto de profanação de Agamben se revele interessante do ponto de vista político, ou seja, como meio de tensionar relações de poderes estabilizadas, acreditamos que sua visão sobre o dispositivo acaba por se distanciar da perspectiva foucaultiana. No artigo em que procura pensar a notícia como dispositivo, Bruck (2011) apresenta um bom resumo da crítica que estamos fazendo.

Agamben formula, assim, sua perspectiva própria e quase (?) apocalíptica em torno dos dispositivos. Para ele, as sociedades contemporâneas se apresentam "como corpos inertes atravessados por gigantescos processos de dessubjetivação que não correspondem a nenhuma subjetivação real" (Agamben, 2009, p. 49). Pelo que, para o autor, é possível que se explique o eclipse da política, que pressupõe sujeitos e identidades reais (o movimento operário, a burguesia etc.), e o triunfo da oikonomia, isto é, de uma mera atividade de governo que visa somente à sua própria reprodução. Agamben não o afirma claramente, mas é evidente que sua percepção de dispositivo, que emerge dos estudos de Foucault, se opõe a sua fonte. Poderíamos mesmo considerá-la anti-foucaultiana. Desconhece ou recusa na sua fonte conceitual a percepção autônoma, dinâmica, cinética, deslizante e de interminável devir dos dispositivos. (Bruck, 2011, p. 13)

Passaremos agora à abordagem de Deleuze, que também trabalha o conceito a partir de Foucault. Em seguida, retomaremos a discussão sobre o dispositivo midiático.

\section{Deleuze e as linhas do dispositivo foucaultiano}

Enquanto Agamben (2005) realiza uma investigação de caráter genealógico, indo até a etimologia do termo, mas depois ampliando-o e se distanciando do próprio Foucault, 
Deleuze centra-se exclusivamente no autor francês. O primeiro dá uma atenção maior à historicidade do termo e em exemplificar o que pode ser considerado "dispositivo", além de propor ações que visem profaná-lo. Já o segundo preocupa-se em traçar as linhas que compõem o que Foucault chama de "dispositivo" a partir das relações de poder nele implicadas.

Esses distintos olhares não inviabilizam aproximações. Ambos destacam o caráter multifacetário do conceito a medida que podemos considerar desde instituições até edifícios físicos e textos escritos como dispositivos. Outro ponto que adquire um papel central na abordagem dos dois autores consiste na capacidade do dispositivo em criar sujeitos (embora, conforme vimos acima, Agamben aponte para uma crise nesse aspecto). É no sujeito (e, portanto, na experiência dos indivíduos) que o dispositivo se individualiza, podendo vir a se transformar e até mesmo se decompor. Segundo Deleuze (1996, p. 2), "podemos nos perguntar se as linhas de subjetivação não são o extremo limite de um dispositivo, e se não esboçam elas a passagem de um dispositivo a outro: neste sentido, elas predispõem as 'linhas de fissura'".

As linhas de fissura expõem o dispositivo a fragilidades, podendo levá-lo, inclusive, à sua decomposição. É pela inserção dos sujeitos que o dispositivo mantém a sua força a fim de que se perpetue, mas é também pela ação desses sujeitos que um dispositivo pode vir a se esfacelar. Em Agamben essa instância é abordada de outra maneira, uma vez que ele sugere que os dispositivos instauram processos de subjetivação cada vez mais frágeis, devendo ser a atitude de profanação o que poderia colocá-lo em crise. Em Deleuze, cuja visada é mais próxima à de Foucault, é na própria formação das subjetividades que residiria o seu potencial transformador.

Além das duas linhas citadas (subjetivação e fissura), Deleuze identifica outras três dimensões que constituem o dispositivo. São elas: as curvas de visibilidade, as curvas de enunciação e as linhas de força.

A primeira dimensão nos diz de um regime de luz. As curvas de visibilidade tornam certos elementos visíveis, assim como apagam outros. Podemos citar o pan-óptico, como exemplo dado pelo próprio Foucault, que consiste em uma prisão em formato circular que tem em seu centro uma torre bem alta, de modo que qualquer pessoa que estivesse presa não conseguiria ver um possível guarda no topo. Além disso, a distância não o permitiria visualizar o preso à sua frente e a espessa parede entre as celas impossibilitaria qualquer comunicação. A ideia consiste no fato de que todos se comportariam bem porque se sentiriam vigiados o tempo todo, o que, inclusive, poderia tornar desnecessária a presença do vigia na torre. Dessa forma, podemos dizer que o pan-óptico, assim como todo dispositivo, oculta algumas coisas (a comunicação com outros presos e a visão do guarda), bem como deixa ver outras (a torre). Convoca a modos de ver, de agir e, passando à segunda dimensão citada, a modos de dizer (o que se permite).

A segunda dimensão que compõe o dispositivo é a das curvas de enunciação. Na visão foucaultiana, os enunciados emitidos constituem e apresentam, neles mesmos, as 
regras de enunciação que os configuram. Falar em "curvas de enunciação" indica que os enunciados "remetem para linhas de enunciação sobre as quais se distribuem as posições inferenciais de seus elementos" (Deleuze, 1996, p. 1).

A tarefa do pesquisador não deve ser a de buscar a origem de cada palavra a fim de uma suposta concepção total que abarque todos os seus sentidos, mas sim verificar em suas regularidades e descontinuidades nos textos que analisa as condições que permitiram com que ela fosse utilizada em determinada ocasião, bem como os sentidos que emergem das relações de poder aí presentes. O pesquisador deve atuar como um cartógrafo, fazendo uma análise de terreno na qual, ao mapear as curvas de visibilidade e as curvas de enunciação presentes nos textos, consiga detectar as linhas de força que atravessam os dizeres e sustentam as relações entre os sujeitos envolvidos, bem como possíveis linhas de fissura do dispositivo em questão.

Por fim, as linhas de força perpassam todos os lugares do dispositivo, atravessando os seus componentes. É a dimensão do poder (e do saber) que é interior ao dispositivo e que tem por função ratificar as linhas das curvas que citamos acima, à exceção das linhas de fissura. Se aquelas tendem a estabilizar as relações de poder inerentes ao dispositivo, estas operam no sentido contrário. Elas podem desestabilizar um dispositivo podendo levar até mesmo ao surgimento de um novo em seu lugar. No entanto, essas linhas de fissura só são possíveis na medida em que há uma individuação do dispositivo pelas linhas de subjetivação, conforme já explicamos.

Como já tínhamos visto em nosso esforço interpretativo a partir das definições do dicionário Michaelis, o dispositivo implica a instauração de um modo próprio de funcionamento. Ele "tem sempre uma função estratégica concreta e se inscreve sempre em uma relação de poder" (Agamben, 2005, p. 10). Ao ordenar os indivíduos, ele os educa, interpelando-os a um modo de ser, de agir, de dizer, estabelecendo um certo e um errado, provendo-os de uma orientação. No entanto, o dispositivo não apenas ordena, como sugere a definição do dicionário, mas também é (re-)ordenado pelos sujeitos, que só são sujeitos pela sua inscrição nos mais diversos dispositivos.

As linhas de subjetivação constituem as linhas de força mais poderosas dos dispositivos e ao mesmo tempo as mais frágeis. Não há sujeitos sem dispositivos e não há dispositivos sem sujeitos neles inscritos. Da mesma forma, é pela experiência dos sujeitos, pelo uso, sempre um uso social, que estes dispositivos são tensionados, abrindo margem para suas linhas de fratura. Estas podem chegar ao extremo de levarem um dispositivo à sua decomposição. A história é rica em exemplos de formas de governos, impérios, sistemas econômicos, prisões, religiões, igrejas e empresas de comunicação que ou tiveram de se transformar para sobreviverem ou não se sustentaram. Dispositivos esses que ao se tocarem também podem dispor um ao outro tanto a linhas de força quanto a linhas de fissura. Tendo esse preâmbulo teórico em mente, passemos à discussão sobre o dispositivo midiático. 


\section{O dispositivo midiático}

O percurso feito até o momento nos ajudou a problematizar o conceito de "dispositivo", bem como observar em que medida a perspectiva de Agamben (2005) ao ampliar sua aplicação acaba se afastando do projeto foucaultiano e, além disso, não consegue contemplar a complexidade inerente aos processos midiáticos. Para pensar a mídia como dispositivo recorremos a outros autores que, ainda que se afastem da visada de Foucault, nos auxiliam a refletir sobre dinâmicas próprias do dispositivo midiático. A partir da revisão e da crítica procuramos apresentar algumas contribuições em que visamos contemplar as especificidades da mídia, mas articulando ao conceito de "dispositivo" acima exposto.

No texto intitulado Mídia: um aro, um halo e um elo, Elton Antunes e Paulo B. Vaz (2006) trabalham com o entendimento da mídia como dispositivo. Para eles, tal visada "compreende as dimensões da comunicação como um certo arranjo espacial, uma forma de ambiência, e um tipo de enquadramento que institui um mundo próprio de discurso" (Antunes, Vaz, 2006, p. 46). Segundo os autores, os dispositivos midiáticos permitem perceber quatro articulações:

1) uma forma específica de manifestação material dos discursos, de formatação de textos; 2) um processo de produção de significação, de estruturação de sentido; 3) uma maneira de modelar e ordenar os processos de interação; e 4) um procedimento de transmissão e difusão de materiais significantes. (Antunes\&Vaz, 2006, p. 47)

Tais dimensões encontram-se profundamente imbricadas. $\mathrm{O}$ dispositivo na visão foucaultiana compreende um suporte material que vai possibilitar a emergência dos discursos e convocar certos modos de ver, ouvir, sentir e, portanto, de (inter) agir no mundo, ou seja, leva a construções de sentido diferenciadas. Cada dispositivo midiático, por sua vez, possui um suporte material específico (rádio, TV, internet, jornal impresso, revista, celulares etc.) por onde textos irão fluir. A partir do dispositivo, definem-se modos de interagir com ele, a linguagem utilizada, ou seja, a gramática segundo a qual textos e sentidos serão construídos. Por meio deste complexo processo os indivíduos têm experiências próprias e produzem interpretações sobre os dispositivos, mas afetados por cada um deles de modo particular.

Isso implica que um mesmo conteúdo em diferentes dispositivos midiáticos leva a distintas experiências e apropriações. A narrativa construída a partir da locução de um jogo de futebol pelo rádio é bem diferente daquela que se produz na TV. Ainda que o jogo seja idêntico, cada dispositivo, ao possuir uma gramática própria, vai capturar os indivíduos de modo distinto e fazer com que eles tenham, portanto, experiências e construções de sentido diferentes. Assim, uma única partida de futebol pode ter sido emocionante para aquele que acompanhou pelo rádio, como também tediosa para aquele que assistiu o jogo pela TV.

Ao mudar-se o dispositivo midiático, as linhas de enunciação se alteram, bem como as curvas de visibilidade, as linhas de força, potenciais linhas de fissura e, por consequên- 
cia, os processos de subjetivação. Indivíduos que estejam mais identificados com certo dispositivo midiático podem sinalizar alguma rejeição ao terem de se adequar a uma nova gramática, que implicará outras ritualidades, modos de ver e ouvir.

Este exemplo aponta tanto para linhas de força quanto para linhas de fissura dos dois dispositivos. No caso do rádio, mostra como a locução radiofônica e, por conseguinte, a locução esportiva aí construída, representa uma poderosa linha de força desse dispositivo. Contudo, isso não substitui a necessidade do público de buscar as imagens, o que sugeriria uma insuficiência ou incompletude que pode eventualmente levar a uma linha de fissura. Em relação à TV, ocorre justamente o contrário: tendo na imagem em movimento sua grande força, a dificuldade de se oferecer uma locução tão emocionante quanto a do rádio surge como um possível ponto de fratura. Assim, um dispositivo midiático acaba por dispor o outro tanto a linhas de fratura quanto a linhas de força.

O exemplo nos mostra a importância de se considerar em análise as especificidades de cada mídia, as ritualidades que ensejam, bem como o modo como os textos circulam e são apropriados pelo público. Além das quatro articulações citadas acima, Antunes \& Vaz (2006) se referem a três dimensões que tratam da inscrição desse dispositivo na sociedade. Segundo eles, podemos falar da mídia como lugar de prescrição de agendamento e formas de controlar a interação, lugar de experiência e do seu caráter de transmissibilidade e reprodutibilidade.

A transmissibilidade e a reprodutibilidade se referem a um modo próprio de inscrição desse dispositivo em um suporte que lhe confere uma materialidade (TV, rádio, impresso, web etc.) e estabelece as possibilidades de interação, conforme visto anteriormente. Desse modo, configuram-se ritualidades próprias do dispositivo midiático, ou seja, modos se ver, ouvir (a depender do meio) e interagir.

O lugar de prescrição e agendamento deriva da visibilidade ampliada própria do dispositivo midiático. Assim, ao atribuírem importância a um determinado tema, os dispositivos midiáticos sugerem ao público o que deve ser tomado por eles como assunto a ser refletido e discutido no dia a dia. Criam, portanto, uma hierarquia. No entanto, ao vir "embalado" com marcas ideológicas, não apenas sugerem o que deve ser refletido, mas também como isso deve ser feito.

Por fim, Antunes e Vaz (2006) compreendem a mídia como um lugar de experiência, que além de possibilitar uma nova vivência, "interpreta e reconfigura a experiência cotidiana" (Antunes, Vaz, 2006, p. 51). A mídia estabelece um fluxo descontínuo por onde correm narrativas que, por sua vez, alimentam as narrativas cotidianas através do agendamento a que nos referimos. Interpelados pelas experiências proporcionadas pelos dispositivos que vêm da interação com a mídias e com os textos e narrativas nelas fixados, os indivíduos se constituem em sujeitos que, mais do que assimilar, vão se apropriar de tais narrativas. Nesse sentido, podemos aproximar a perspectiva de Antunes e Vaz (2006) com a de Foucault quanto a esse lugar de experiência como potencial gerador de subjetividades e sujeições. 
A perspectiva de Antunes e Vaz (2006) é interessante por abranger desde uma dimensão técnica imediata do dispositivo midiático até as apropriações que são feitas de seus produtos, aspecto que a leitura de Agamben não contempla.

Já Maurice Mouillaud (1997) também trabalha com o termo e critica uma visão tecnicista que vê o dispositivo apenas como suporte no qual os sentidos vão sendo depositados. Segundo o autor,

O dispositivo não é o suporte inerte do enunciado, mas um local onde o enunciado toma forma. Os dispositivos da mídia também não exercem o simples papel de contextos. Enquanto que o enunciado e seu contexto podem ser - em uma certa medida - destacados um do outro (um mesmo enunciado podendo aparecer em diversos contextos), e o contexto traz ao enunciado apenas uma variável de sentido, o local desempenha o papel de uma matriz, de tal maneira que um certo tipo de enunciado só possa aparecer in situ... (Mouillaud, 1997, p. 85, grifos nossos).

Embora a perspectiva de Mouillaud (1997) não seja tão abrangente quanto a de Antunes e Vaz (2006), sua visada compreende o próprio suporte, no qual textos e narrativas emergem, como produtor de sentido e não apenas como um lugar em que eles se fixam. Assim, a interface que cada dispositivo midiático apresenta interfere no modo como os sujeitos irão interagir com ele e também nos sentidos que irão construir sobre os textos e narrativas. Dessa forma, o dispositivo corresponderia a uma unidade conceitual que une o contexto, o enunciado, o suporte e a forma de inscrição (Ferreira, 2006, p. 144). O dispositivo midiático corresponderia a essa matriz geradora de sentidos que se situa no entremeio: linguagem-sociedade-tecnologia. Assim, ao analisar uma página de um jornal impresso, o autor sugere que seria profícuo ao analista levar em consideração elementos que estão para além do texto verbal, tais como: o jornal em que a matéria foi publicada, a seção em que a página foi colocada, o espaço que lhe é dedicado, a diagramação etc.

Importante salientar que Mouillaud também observa que o processo não se dá apenas em mão-única, ou seja, com o dispositivo enformando a mensagem, mas também no sentido contrário. O dispositivo não apenas gera o texto, mas também se gera no texto na consequente interação com o leitor. O problema que identificamos na perspectiva do autor é que ela não avança a partir desse ponto. Como afirma Ferreira (2006, p. 144), Mouillaud olha para o tecnológico e para a linguagem, mas não os relaciona com a sociedade que os engendra.

Se levarmos em conta o ponto abordado, mas relacionarmos à perspectiva foucaultiana, podemos dizer: se o próprio texto gerado pelo dispositivo pode modificar o modo como o leitor se relaciona com ele, seus textos poderiam levá-lo tanto a linhas de força quanto a linhas de fissura. Ao ensejar a emergência de uma nova postura do leitor em relação ao dispositivo por meio da experiência interpretativa, temos novas linhas de subjetivação.

Neste sentido, cabe-nos perceber os avanços, mas também indicar pontos que possam ser explorados. Em Mouillaud, o aspecto social não é contemplado, contudo, abre-se 
um caminho interessante com a perspectiva dialética do dispositivo, que pensa nele como matriz de sentido que configura textos e é por eles (re)configurado. Antunes e Vaz (2006), embora não articulem sua discussão às relações de poder de que fala Foucault, contribuem com uma visão do dispositivo midiático que o situa a partir dos complexos processos comunicacionais por ele ensejados e o modo como estes se articulam na sociedade. Ferreira (2006), ao analisar o que se pensa por dispositivo midiático, faz uma cuidadosa revisão bibliográfica e observa que há três dimensões por meio das quais o dispositivo midiático é pensado: sócio-antropológica, meio-linguística e técnico-tecnológica. De acordo com ele, os autores normalmente trabalham dois aspectos e costumam ignorar um deles. Aqui ressaltamos a necessidade de se pensar o dispositivo midiático também a partir de três instâncias, mas com o desafio de não descuidar de nenhuma delas, tendo sempre em mente as relações de poder que as perpassam.

\section{Conclusões e apontamentos adicionais}

A título de uma ponderação final, mais do que de uma conclusão, podemos observar que a perspectiva que o conceito de "dispositivo" abre se revela muito profícua para se pensar a mídia e sua processualidade. Tendo em vista as reflexões feitas até aqui, pensamos poder distinguir no dispositivo midiático as seguintes instâncias:

\section{Dimensão Tecnodiscusirva}

1) Mais do que produzir sentido sobre si próprio (autoreferencialidade), constrói textos e narrativas sobre o mundo (curvas de enunciação);

2) Máquina tecnodiscursiva: uma dimensão tecnológica é inerente a esta máquina discursiva e não corresponde a apenas um suporte em que sentidos são fixados, mas, em vez disso, compõe uma estrutura significante. Cada meio convoca a um uso social (a sujeitos) diferenciado e possui uma "gramática" (linguagem) específica (Mouillaud, 1997). Assim, do ponto de vista de uma construção de sentidos, forma e conteúdo estão intimamente imbricados, sendo que tanto um quanto o outro podem levar a reconfigurações do dispositivo;

3) Lógicas interacionais: cada dispositivo midiático estabelece uma ritualidade (exemplo: os aparelhos de rádio e TV criam uma ritualidade própria e diferenciada) à medida que os indivíduos "apre(e)ndem" a utilizá-los, estabelecendo, cada um com sua peculiaridade, modos distintos de apropriação (Antunes \& Vaz, 2006).

\section{Dimensão Político-Ideológica}

1) Relações de poder: só é possível pensar em dispositivo nas relações de poder em que ele se inscreve e que ele circunscreve. Assim, falar em dispositivo é pensar em quem e no que ele toca, como distribui lugares e hierarquiza sujeitos e ideias. O dispositivo está intimamente ligado a relações de poder entre os diversos âmbitos da sociedade 
(a política, a religião, concorrência com outras mídias etc.), materializando-se também nos textos gerados. Por meio de uma análise discursiva podemos entrever pistas materiais de tais relações por meio de continuidades e descontinuidades;

2) Individuação e processos de subjetivação: nas experiências a que o dispositivo interpela os indivíduos, ritualidades próprias conjugam-se a modos específicos de olhar, ouvir, sentir e, por conseguinte, de interpretar as textualidades que emergem, criando assim constantes interpretativas, hábitos que vão constituir sujeitos e subjetividades. As experiências dos sujeitos inscritos no dispositivo midiático podem reforçar tal sujeição ou resultar em mudanças (quiçá, crises) dependendo da forma como estes se apropriam deles. Essa perspectiva nos é interessante porque não se restringe à esfera da produção, mas toca no processo circular e reflexivo que é próprio da comunicação.

\section{Dimensão Relacional}

1) Grande permeabilidade a outros dispositivos: a mídia toca outros dispositivos a todo momento, em alguns casos realiza conexões mais intensas e gera outros dispositivos. Isso pode ocorrer em várias instâncias, por exemplo, na política (assessorias que preparam os candidatos para aparições públicas pensando nas repercussões), a religião (por meio de programas de TV e páginas do Facebook produzidos por igrejas e fiéis, missas que são modificadas para serem transmitidas ao vivo) e o esporte (vale lembrar, por exemplo, como a confederação americana de futebol americano redefiniu as regras do jogo em virtude das transmissões televisivas);

2) Visibilidade ampliada e agendamento: a grande inserção dos dispositivos midiáticos na sociedade faz com que o que neles apareça goze de uma visibilidade ampliada. Ao dar mais importância a certos temas do que a outros, o dispositivo midiático (as curvas de visibilidade) estabelece hierarquias e aponta para aquilo que devemos considerar mais relevante e a forma como devemos pensar sobre isso;

3) Redefinição das noções de espaço e tempo: ao constituir sujeitos por meio das experiências a que o dispositivo interpela o sujeito (seja tal experiência narrativa ou não), esse dispositivo remodela as noções de espaço e tempo, e institui hábitos (de acompanhar os programas de rádio e TV que seguem uma determinada grade de programação) e ambiências - sejam elas virtuais ou não, como, por exemplo: 1) a mudança no modo como me relaciono com a minha cidade a partir do momento que me desloco orientado pelo GPS ou com base em informações no rádio; 2) o conflito de temporalidades entre religião e mídia que ocorre quando fiéis elaboram maneiras de fazer orações em grupos de WhatsApp (Sousa, 2018).

Por fim, cabe dizer que as dimensões citadas estão profundamente imbricadas de modo que ainda que tenhamos como foco uma ou outra nas nossas análises devemos considerá-las em perspectiva com as demais. Pensar a mídia como dispositivo midiático implica ir além da perspectiva tecnicista que criticamos, mas sem abandoná-la, visto que é 
parte constituinte do dispositivo midiático. Nesse sentido, podemos falar em dispositivos midiáticos sociotécnicos, significando complexos jogos de disputas de sentido e de poder que envolvem negociações da mídia com diversos outros atores sociais.

\section{Bibliografia}

Agamben, G. (2005, ago-dez). O que é um dispositivo? Florianópolis: Outra Travessia, no 5, pp. 9-16.

Antunes, E.; Vaz, P. B. (2006). Mídia: um aro, um halo e um elo. In: Guimarães, C.; França, V. (Ed.). Na mídia, na rua - narrativas do cotidiano. Belo Horizonte: Autêntica.

Bruck, M. S. (2011). A notícia como dispositivo de enunciação contemporâneo. In: Anais do XX Encontro da Compós. Porto Alegre.

Cezar, T. (1995, dez). Estruturalismo e Pós-estruturalismo na perspectiva do conhecimento histórico. In: Anos 90 - Revista do Programa de Pós-graduação em História/UFRGS, nº 4, v. 3.

Deleuze, G. (1996). O mistério de Ariana. Lisboa: Editora Vega. Recuperado em 20 de julho de 2015. Disponível em: http://www.ufes.br/ppgpsi/files/textos/Deleuze\%20-\%200\%20que\%20\%C3\%A9\%20 um\%20dispositivo.pdf

Ferreira, J. (2006). Uma abordagem triádica dos dispositivos midiáticos. In: Líbero. FACASPER, v. 1, pp. $1-15$.

Foucault, M. (2012). A arqueologia do saber. $8^{a}$ ed. Rio de Janeiro: Forense Universitária.

Michaelis, Dicionário On-line. Definição do verbete "dispositivo". Recuperado em 10 de julho de 2013. Disponível em: <http://michaelis.uol.com.br/>.

Mouillaud, M. (1997). Da forma ao sentido. In: Mouillaud, M., Porto, S. D. (ed.). O jornal da forma ao sentido. Brasília: Paralelo 15, p. 29-36.

Mouillaud, M. (1997). O nome do jornal. In: Mouillaud, M., Porto, S. D. (ed.). O jornal da forma ao sentido. Brasília: Paralelo 15, pp. 85-98.

Sousa, M. T. de. (2018). Rezando pelo smartphone: reconfigurações de práticas religiosas em grupo de orações pelo WhatsApp. Texto aprovado para publicação nos anais do XXVII Encontro da Compós, Belo Horizonte. 